Sir,

\section{Central retinal vein obstruction with cilio-retinal infarction}

In a letter to your journal, Singh ${ }^{1}$ described a 28 -year-old woman with central retinal vein obstruction (CRVO) and infarction of the inner retina in the territory of a superior macular arteriole. He felt that the affected arteriole was a branch of the central retinal artery (CRA) rather than a cilio-retinal arteriole, even though the vessel filled with fluorescein before the CRA proper and its four immediate branches. One cannot be certain of the origin of such a vessel without anatomical proof, ${ }^{2}$ but equally it is difficult to reconcile such early dye filling with an origin other than from the posterior ciliary arterial (as opposed to the CRA) circulation. Early cilio-retinal dye filling in cases of CRVO with cilio-retinal infarction has previously been reported ${ }^{3,4}$ along with a 'pulsatile' dye transit (or intermittent retrograde flow) in the cilio-retinal arterioles. $^{3-6}$ These angiographic features, and especially the paradox of early dye filling with impaired perfusion, help in revealing the nature of the relationship between CRVO and cilio-retinal infarction where similar haemodynamic principles to those underlying sphygmomanometry and ophthalmodynomometry apply. 5,7

Consider firstly the effect of CRVO on inner retinal perfusion in an eye with a cilio-retinal arteriole arising directly from the ophthalmic artery near the origin of the CRA. The perfusion pressure (arteriovenous gradient) in the cilio-retinal territory would essentially be the same as that in the CRA territory and, provided the intraluminal CRV pressure did not exceed the diastolic ophthalmic artery pressure, this would most likely be sufficient to maintain the viability of the entire inner retina. Next, consider the effect of CRVO in an eye with a cilio-retinal arteriole arising as a branch of a major vessel in the choroid. The perfusion pressure in such a cilio-retinal arteriole will reflect the systolic and diastolic arterial pressures in the parent choroidal artery (part of the 'high-flow, low-resistance' circulation unaffected by CRVO) and not the ophthalmic arterial pressures. Hence, 'pulsatile' flow (ie intermittent reversal of flow) in the cilio-retinal territory might arise, perfusion being below the level needed to sustain inner retinal viability. Nevertheless, the cilio-retinal dye front might still precede that in the CRA. Whether the dye front precedes, ${ }^{1,3,4}$ coincides with ${ }^{5,6}$ or follows ${ }^{5,6}$ CRA filling will depend on the phase of the cardiac cycle at which the bolus of fluorescein arrives at the arterial branch point during a particular angiographic study. In practice, the site of origin and branching pattern of the posterior ciliary circulation vary considerably ${ }^{2}$ but may be crucial to the outcome of CRVO.
In young individuals, the retinal capillaries are capable of withstanding high transmural pressure gradients after (partial) CRVO, so there may be little by way of retinal oedema or haemorrhage (unless provoked by paracentesis ${ }^{8}$ ). Thus, the symptomatic presentation of unilateral CRVO in Singh's ${ }^{1}$ patient most likely depended on her possessing not only a macular cilio-retinal arteriole but also the one derived from a choroidal artery (rather than the one with a more direct origin from the ophthalmic artery).

\section{References}

1 Singh AJ. Branch retinal artery obstruction with simultaneous central retinal vein occlusion. Eye 2001; 15: 225-227.

2 Hayreh SS. The cilio-retinal arteries. Br J Ophthalmol 1963; 47: 71-89.

3 Zylbermnann R, Rozenman Y, Ronen S. Functional occlusion of a cilioretinal artery. Ann Ophthalmol 1981; 13: $1269-1272$

4 Noble KG. Central retinal vein occlusion and cilio-retinal artery infarction. Am J Ophthalmol 1994; 118: 811-813.

5 McLeod D, Ring CP. Cilio-retinal infarction after retinal vein occlusion. Br J Ophthalmol 1976; 60: 419-427.

6 Schatz H, Fong ACO, McDonald HR et al. Cilio-retinal artery occlusion in young adults with central retinal vein occlusion. Ophthalmology 1991; 98: 594-601.

7 Duke-Elder S, Gloster J. In: System of Ophthalmology, Vol. IV. Kimpton: London, 1968, pp 14-18.

8 McLeod D. Cilio-retinal arterial circulation in central retinal vein occlusion. Br J Ophthalmol 1975; 59: 486-492.

\section{Mcleod}

Academic Department of Opthalmology

Manchester Royal Eye Hospital

Oxford Road

Manchester M13 9WH, UK

Correspondence: D McLeod

Tel: 01612765620

Fax: 01612736354

E-mail: d.mcleod@man.ac.uk

Eye (2003) 17, 283. doi:10.1038/sj.eye.6700304

Sir,

\section{Reply}

I would like to thank Professor McLeod for the interest shown in this case report and for comments regarding the nature of arterial occlusion in eyes with central retinal vein occlusion (CRVO).

The reason that led me to conclude that this was a branch artery as opposed to a cilio-retinal artery was the 
fact that the affected vessel filled with fluorescein dye at $9.8 \mathrm{~s}$. This was well after the choroidal flush of the angiogram when a cilio-retinal vessel would have filled with dye. This time $(9.8 \mathrm{~s})$ is consistent with the early arterial phase of the fluorescein angiogram. ${ }^{1}$ A closer inspection of Figure $3 \mathrm{a}$ also shows the proximal inferotemporal, superonasal and inferonasal arterial branches containing fluorescein simultaneously with the affected vessel. This indicates that the phase difference of the filling vessel and the other retinal arterial branches was not very significant, as would be the case in cilioretinal and central retinal vessel filling. This difference is usually in the order of $1-3 \mathrm{~s} .^{1}$ All four major retinal arterial branches filling with dye simultaneously is more consistent with a common origin from the central retinal artery as opposed to an origin from the posterior ciliary (in the case of cilio-retinal arteries) and central retinal arteries, in which the time difference of dye filling is at least $1-3 \mathrm{~s} .{ }^{1}$ This was not observed in this case where the time difference was not measurably more than $1 \mathrm{~s}$.

The affected vessel also traces back to the bifurcation of the major retinal vessels (Figure $3 a-c$ ) at the centre of the optic disc head. This is readily visible in Figure 3 in spite of the presence of a dilated central retinal vein. Cilio-retinal arteries usually arise from the rim of the optic cup at the lateral border of the optic nerve, ${ }^{2,3}$ which was not observed in this patient.

The occluded vessel filled with fluorescein before any other branch, but this phase difference was very small, as mentioned earlier. ${ }^{4,5}$ Ordinarily, this should not be so, and in the light of the relatively short phase difference of the dye front, the difference in perfusion pressure between vessels would have to be small. Perhaps the explanation could be anomalous branching of the main central artery with this particular arterial branch arising proximally within the optic nerve head before other branches were given off. This could explain why this vessel filled with dye just before the other main branches.

Central collateral branches of the central retinal artery are known to occur. These vessels arise proximally within the optic nerve and may pass with the central artery towards the lamina cribrosa. ${ }^{2}$ It has already been pointed out that this can only be confirmed anatomically. However, there is an anomalous pattern to the arterial branching in this eye at the optic nerve head, and the optic disc in the affected eye was smaller compared to the disc on the other side. A proximal branching origin would also support the theory of vascular compression from optic disc swelling, since the said vessel would have to traverse the lamina cribrosa of the optic nerve, where compression would be likely in a swollen optic disc. Anomalous branching of retinal arteries is a rare but recognised cause of arterial occlusion in the eye. ${ }^{6}$ This was also the explanation given as to the possible aetiology in this case report, and the possibility of anomalous or collateral arterial branching should be considered.

The effect of retinal vessel autoregulation may also have contributed to the affected vessel filling slightly ahead of the other vessels. In the presence of hypoxia, as for example in an area of arterial occlusion, metabolic autoregulatory mechanisms in retinal vasculature lead to an accumulation of vasodilatory metabolites. ${ }^{3}$ As a consequence, arteriolar tone is reduced and vascular resistance reduces accordingly. ${ }^{3}$ This would result in a greater relative blood flow in this particular vessel, allowing it to fill ahead of the other retinal branches. Choroidal blood flow is not autoregulated. ${ }^{3}$

Despite thorough investigations, the exact pathophysiologic mechanism of the vascular insult in this particular case remains unknown.

\section{References}

1 Ryan SJ. Retina, 2nd edn, Vol. 2, Mosby: St Louis, MO, 1994.

2 Snell RS, Lemp MA. Clinical Anatomy of the Eye. Blackwell Scientific Publications, Inc: Boston, 1989.

3 Alm A. Ocular circulation. In: Hart Jr WM (ed). Adlers Physiology of the Eye, 9th edn, Mosby Yearbook Inc.: St Louis, MO, 1992, pp 198-227.

4 Shatz H, Fong AC, McDonald HR et al. Cilio retinal artery occlusion in young adults with central retinal vein occlusion. Ophthalmology 1991; 98(5): 594-601.

5 McLeod D, Ring CP. Cilio retinal infarction after retinal vein occlusion. Br J Ophthalmol 1976; 60: 419-427.

6 Brown GC, Magargal LE, Augsburger JJ et al. Pre-retinal arterial loops and retinal arterial occlusion. Am J Ophthalmol 1979; 87(5): 646-651.

A Singh

Department of Ophthalmology

Hull Royal Infirmary

Anlaby Road

Hull HU3 2JZ, UK

Correspondence: A Singh

E-mail: mraniljsingh@yahoo.co.uk

Eye (2003) 17, 283-284. doi:10.1038/sj.eye.6700305

Sir,

Orbital cellulitis following corneal gluing under subTenon's local anaesthesia

Regarding the case report by Redmill et al, ${ }^{1}$ it should not be intuitively surprising that purulent orbital cellulitis resulted from a sub-Tenon's local anaesthetic given in the presence of active corneal ulceration. The authors do not 